\title{
The Preventive Effects of Diminazene Aceturate in Renal Ischemia/Reperfusion Injury in Male and Female Rats
}

\author{
Maryam Malek ${ }^{1}$ and Mehdi Nematbakhsh ${ }^{1,2}$ \\ ${ }^{1}$ Water \& Electrolytes Research Center, Department of Physiology, Isfahan University of Medical Sciences, Iran \\ ${ }^{2}$ Isfahan MN Institute of Basic \& Applied Sciences Research, Isfahan, Iran \\ Correspondence should be addressed to Mehdi Nematbakhsh; nematbakhsh@med.mui.ac.ir
}

Received 20 July 2014; Revised 10 October 2014; Accepted 14 October 2014; Published 13 November 2014

Academic Editor: Ivaylo Gentschev

Copyright (c) 2014 M. Malek and M. Nematbakhsh. This is an open access article distributed under the Creative Commons Attribution License, which permits unrestricted use, distribution, and reproduction in any medium, provided the original work is properly cited.

\begin{abstract}
Background. Angiotensin-converting enzyme 2/angiotensin (1-7)/Mas receptor (ACE2/Ang-1-7/MasR) appears to counteract most of the deleterious actions of angiotensin-converting enzyme/angiotensin II/angiotensin II receptor 1 (ACE/Ang II/AT1R) in renal ischemia/reperfusion (I/R) injury but ACE2 activity and its levels are sexually dimorphic in the kidney. This study was designed to evaluate the effects of activation endogenous ACE2 using the diminazene aceturate (DIZE) in renal I/R injury in male and female rats. Methods. 36 Wistar rats were divided into two groups of male and female and each group distinct to three subgroups $(n=6)$. I/R group was subjected to $45 \mathrm{~min}$ of bilateral ischemia and $24 \mathrm{~h}$ of reperfusion, while treatment group received DIZE ( $15 \mathrm{mg} / \mathrm{kg} / \mathrm{day}$ ) for three days before the induction of I/R. The other group was assigned as the sham-operated group. Results. DIZE treatment in male rats caused a significant decrease in blood urea nitrogen (BUN), creatinine, liver functional indices, serum malondialdehyde $(\mathrm{MDA})$, and increase kidney nitrite levels $(P<0.05)$, and in female rats a significant increase in creatinine and decrease serum nitrite levels compared to the I/R group $(P<0.05)$. Conclusions. DIZE may protect the male kidney from renal I/RI through antioxidant activity and elevation of circulating nitrite level.
\end{abstract}

\section{Introduction}

Renal ischemia/reperfusion (I/R) injury occurs in hypovolaemia conditions, septic shock, renal transplantation, or cardiovascular surgery, and it is the most common cause of acute kidney injury (AKI) which is associated with increased morbidity and mortality rates and subsequent development of chronic kidney disease (CKD) [1-3]. Evidences have shown that there is a protective effect of female sex hormone on I/R-induced AKI [4], but there is lower renal angiotensinconverting enzyme 2 (ACE2) level in the female than male rats [5]. Whereas there have been abundant pathophysiologic studies on renal I/R injury, a definitive treatment has not been found [6]. Several causal factors such as reactive oxygen species (ROS), cytokines, and chemokines synthesis contribute to the pathogenesis of renal damage $[7,8]$, among these mechanisms interaction between both arms of rennin angiotensin system (RAS), ACE-angiotensin II (Ang II)-Ang II receptor 1 (AT1R) and ACE2-angiotensin 1-7 (Ang 1-7)-Mas receptor (MasR) axis, has progressively assumed an important role $[9,10]$. Many studies have shown that Ang II contributes to renal injury in AKI models [11, 12]. ACE2 is a homologue of ACE which cleaves a single amino acid from AngII and forms a heptapeptide with vasodilatory actions of Ang 1-7 playing a protective role in AKI [10]. Local balance between ACE and ACE2 as well as Ang II and Ang 1-7 is crucial for controlling AngII levels and its effects on renal injury; therefore ACE2 upregulators that can proper ACE/ACE2 balance are potential therapeutic strategy for kidney injury [13]. Diminazene aceturate (DIZE), an activator of endogenous ACE2, is widely used as a trypanolytic agent in livestock that can activate the protective axis of RAS and counter-regulates the deleterious effects of Ang II [14]. We hypothesized that intrinsic ACE2 activator such as DIZE would have protective effects on I/R-induced AKI, and to test these hypotheses male and female rats were subjected to I/R injury and the effect of DIZE was compared with control group. 

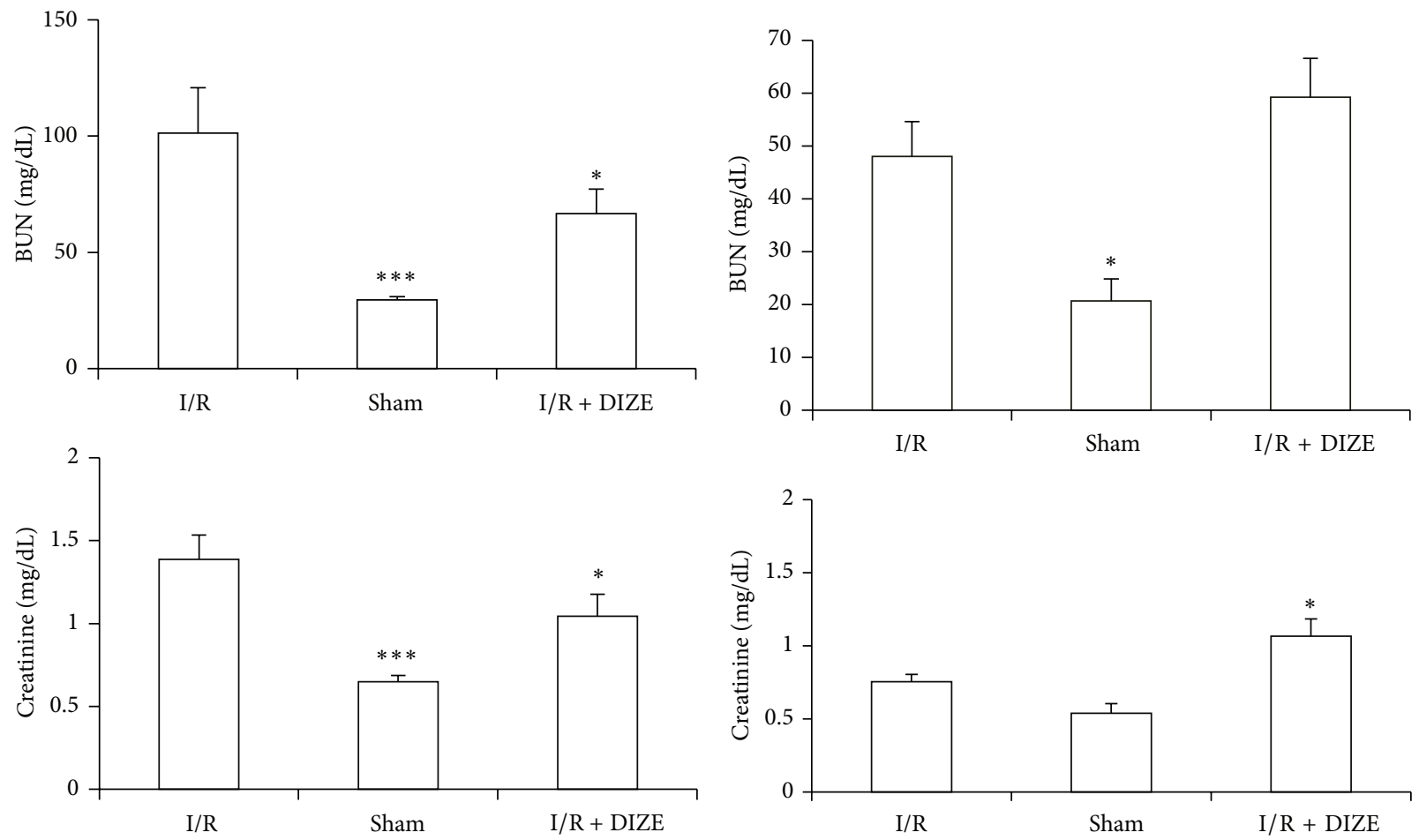

(a)

(b)

FIGURE 1: Changes in blood urea nitrogen (BUN) and creatinine levels in the male (a) and female (b) I/R (45 min ischemia followed by 24 hours of reperfusion), sham operated, and diminazene ( $15 \mathrm{mg} / \mathrm{kg} /$ day for 3 days) treated groups before ischemia (I/R + DIZE) (for each group $n=6) .{ }^{*} P<0.05,{ }^{* * *} P<0.001$ versus I/R group.

\section{Methods}

2.1. Animals. 36 Wistar rats were maintained at a room temperature of $23^{\circ} \mathrm{C} \pm 2^{\circ} \mathrm{C}$, with a $12 \mathrm{~h}$ light-dark cycle. Tap water and chow were freely available throughout the acclimatization and study periods. Experiments were carried out in accordance with Isfahan University of Medical Sciences Ethics Committee.

Animals were divided into two distinct groups of males and females (weighting $180 \pm 30 \mathrm{~g}$ ) and each group was divided into three subgroups (6 in each subgroup) as follows: group (1) I/R $45 \mathrm{~min}$ of bilateral renal ischemia followed by reperfusion, group (2) sham operation group; group (3) I/R 3 days pretreated with DIZE (Aburaihan Pharmaceutical Company, Tehran, Iran) (15 mg/kg) [15] group.

2.2. Surgical Procedures. The rats were anesthetized using $10 \mathrm{mg} / \mathrm{kg}$ of xylazine and $100 \mathrm{mg} / \mathrm{kg}$ of ketamine hydrochloride intraperitoneally [16]. Two small flank incisions were made and both kidneys were excited. The renal pedicles, containing the artery, vein, and nerve supplying each kidney, were carefully isolated and clamped for 45 minutes. Occlusion was verified visually by change in the color of the kidneys to a paler shade and reperfusion by a blush. So the animals without restoration blood flow were excluded from the experiment. In sham operation group rats underwent identical surgical procedures as I/R group without bilateral renal clamping. In group 3, rats were pretreated with injection of DIZE solution in distillated water $(15 \mathrm{mg} / \mathrm{kg} / \mathrm{day})$ for 3 days. In 3rd day and 2 hours after the last injection, renal I/R were induced. Twenty-four hours after bilateral pedicle occlusion and reperfusion all rats were reanesthetized, blood samples were collected from the heart, and the serum was separated immediately, stored at $-20^{\circ} \mathrm{C}$ until being assayed. Then animals were sacrificed by injection of potassium chloride (KCL 10\%) into the heart; both kidneys and gonads were removed and weighed. The right kidneys were homogenized and centrifuged at $6000 \mathrm{~g}$ for 10 minutes; supernatant was centrifuged again at $15000 \mathrm{~g}$ for 2 minutes. The left kidneys were fixed in $10 \%$ formalin for histological analysis. All animals were weighed at the start and end of the experimental period.

2.3. Histological Examination. Formalin-fixed renal tissue was dehydrated, embedded in paraffin, and sliced into $4 \mu \mathrm{m}$ thick sections which were stained with hematoxylin and eosin. Histological lesion (acute tubular necrosis) was graded on a scale of 0 to 4 as follows [17]: $0=$ normal kidney; $1=$ minimal damage $(<5 \%$ involvement of the cortex or outer medulla); $2=$ mild damage (5-25\% involvement of the cortex or outer medulla); $3=$ moderate damage (25$75 \%$ involvement of the cortex or outer medulla); $4=$ severe damage ( $>75 \%$ involvement of the cortex or outer medulla). 

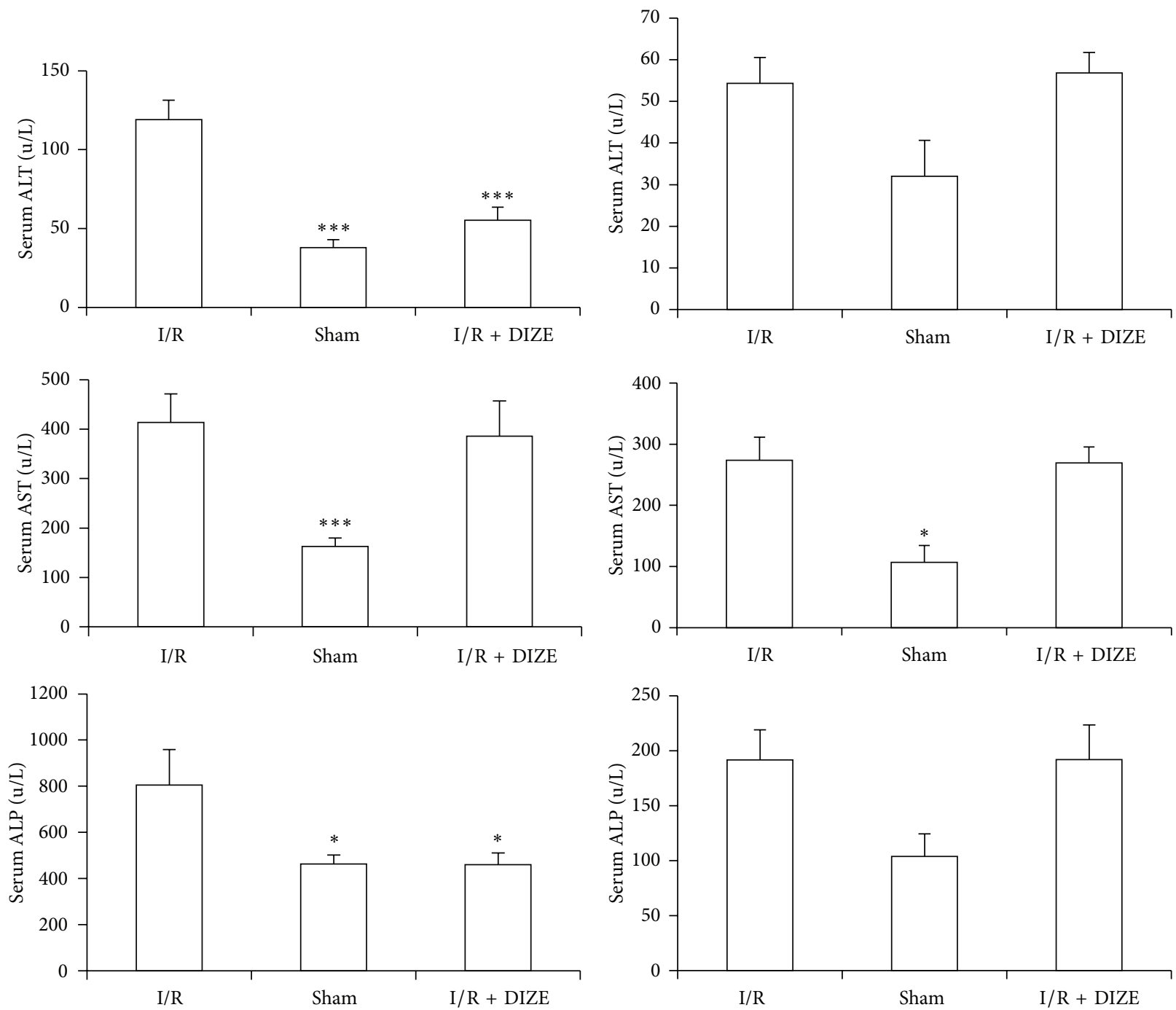

(a)

(b)

FIgURE 2: Changes in serum ALT, AST, and ALP in male (a) and female (b) IR (45 min ischemia followed by 24 hours of reperfusion), sham operated, and diminazene ( $15 \mathrm{mg} / \mathrm{kg} /$ day for 3 days) treated groups before ischemia (I/R + DIZE). ${ }^{*} P<0.05,{ }^{* * *} P<0.001$ versus $\mathrm{I} / \mathrm{R}$ group.

2.4. Laboratory Analysis. Serum creatinine, urea, alkaline phosphatase (ALP), aspartate aminotransferase (AST), and alanine aminotransferase (ALT) of all samples were measured using an autoanalyzer (Pars Azmun, Iran). Serum level of nitrite was assayed by using colorimetric assay kit (Promega Corporation, USA).

MDA levels in serum and kidney supernatant were assayed manually by the measurement of thiobarbituric acidreactive substances (TBARS) levels at $532 \mathrm{~nm}$, briefly $500 \mu \mathrm{L}$ of each sample was mixed to $10 \%$ trichloroacetic acid and centrifuged at $2000 \mathrm{~g}$ for $10 \mathrm{~min}$, and $500 \mu \mathrm{L}$ of supernatant was added to $500 \mu \mathrm{L}$ of $0 / 67 \%$ thiobarbituric acid and incubated in warm water bath for $10 \mathrm{~min}$.

2.5. Statistical Analysis. Data were expressed as the mean \pm SEM. Differences between groups were compared by oneway analysis of variance using SPSS software version 20 for windows. Pathological damages scores between the groups were compared by Mann-Whitney, and $P<0.05$ was considered statistically significant.

\section{Results}

3.1. Effect of I/R and Diminazene Treatment on Renal Function. There was an increase in BUN and creatinine levels following ischemia in both sexuality groups, but it showed only in male groups a significant increase when compared to the sham group $(101.25 \pm 19.5$ versus $29.5 \pm 1.42 \mathrm{mg} / \mathrm{dL}$ and $1.39 \pm 0.14$ versus $0.65 \pm 0.037 \mathrm{mg} / \mathrm{dL}, P<0.001)$. The elevation in BUN and creatinine levels in male groups was reduced significantly by DIZE pretreatment (66.74 \pm 10.5 versus $101.25 \pm 19.5 \mathrm{mg} / \mathrm{dL}$ and $1.04 \pm 0.134$ versus $1.39 \pm$ $0.14 \mathrm{mg} / \mathrm{dL}$ ); female treated group showed worsen response in BUN and creatinine levels with significant increase in 

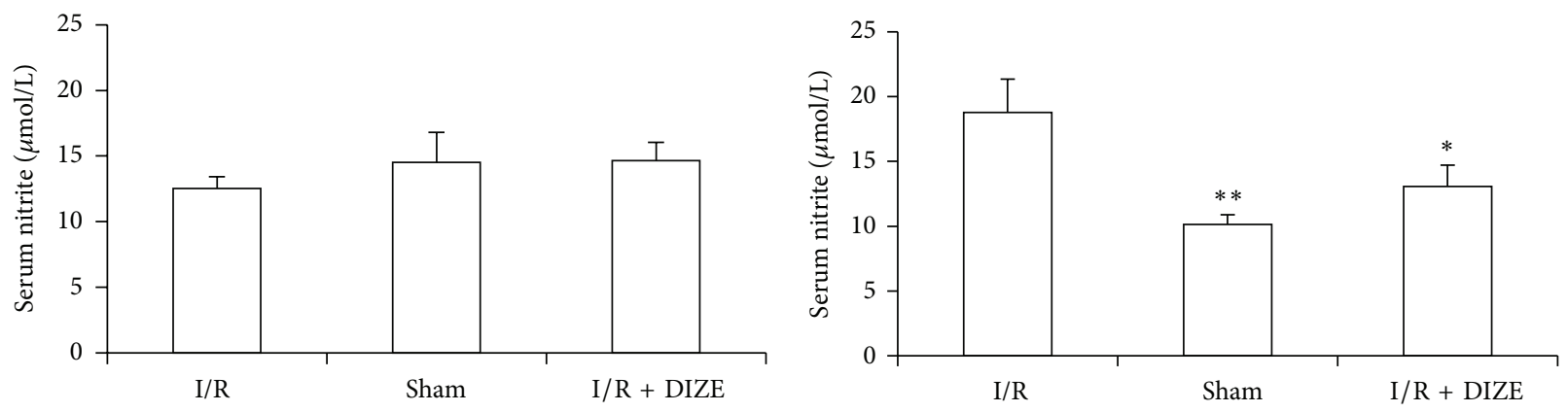

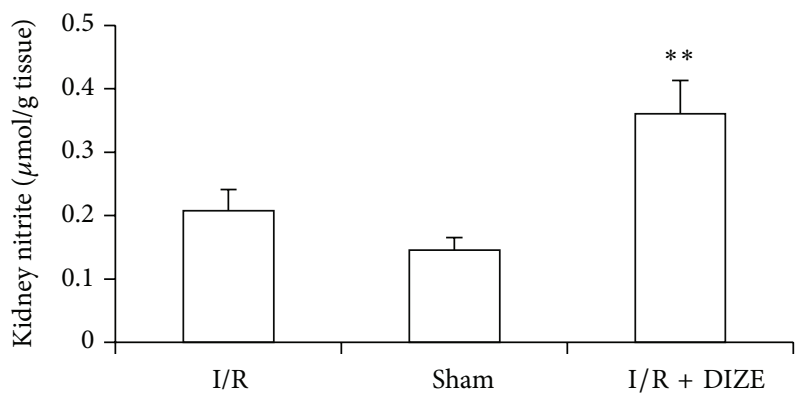

(a)

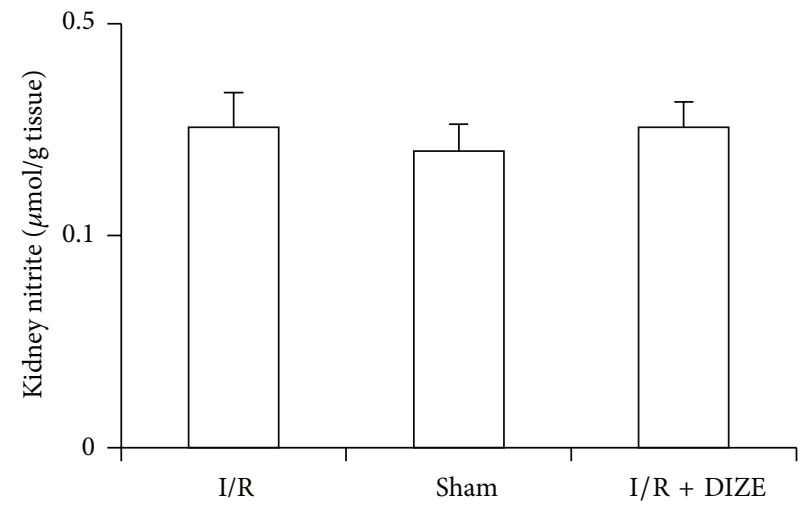

(b)

Figure 3: Changes in serum and kidney nitrate levels inmale (a) and female (b) I/R ( $45 \mathrm{~min}$ ischemia followed by 24 hours of reperfusion), sham operated, and diminazene ( $15 \mathrm{mg} / \mathrm{kg} /$ day for 3 days) treated groups before ischemia (I/R $+\mathrm{DIZE}) .{ }^{*} P<0.05,{ }^{* *} P<0.01 \mathrm{versus} \mathrm{I} / \mathrm{R}$ group.

creatinine level as compared to the I/R group $(1.065 \pm 0.118$ versus $0.755 \pm 0.049 \mathrm{mg} / \mathrm{dL}, P<0.05$ ) (Figures $1(\mathrm{a})$ and $1(\mathrm{~b})$ ).

\subsection{Effect of Renal $I / R$ and DIZE Treatment on Hepatic} Function. As shown in Figures 2(a) and 2(b), serum levels of ALT, AST, and ALP elevated after ischemia in contrast to sham groups; however only male groups had significant difference $(119 \pm 12.24$ versus $38 \pm 4.9 \mathrm{u} / \mathrm{L}, 413.67 \pm 57.86$ versus $162.67 \pm 16.82 \mathrm{u} / \mathrm{L}$ and $805.33 \pm 153.87$ versus $463.17 \pm$ $39.2 \mathrm{u} / \mathrm{L}, P<0.05)$. DIZE administration before ischemia could decrease male serum levels of ALT and ALP when compared to IR groups $(55.33 \pm 8.19$ versus $119 \pm 12.24 \mathrm{u} / \mathrm{L}$, and $460 \pm 50.63$ versus $805.33 \pm 153.87 \mathrm{u} / \mathrm{L}, P<0.05)$.

\subsection{Effect of Renal I/R and DIZE Treatment on Serum and} Kidney Levels of Nitrite. The serum nitrite level in female ischemia rats was higher significantly than the sham group $(18.76 \pm 2.58$ versus $10.14 \pm 0.72 \mu \mathrm{mol} / \mathrm{L}, P<0.05)$ and administration of DIZE attenuated it $(13.08 \pm 1.62$ versus $18.76 \pm 2.58 \mu \mathrm{mol} / \mathrm{L}, P<0.05)$. There was no significant difference in male rats.

The kidney nitrite in male DIZE treated rats was elevated significantly when compared to I/R groups $(0.36 \pm 0.052$ versus $0.208 \pm 0.033 \mu \mathrm{mol} / \mathrm{g}$ tissue, $P<0.05)$ but there was no significant difference in female rats (Figures 3(a) and 3(b)).
3.4. Effect of Renal I/R and DIZE Treatment on Gonads, Kidneys, and Body Weights. Body weight decreased significantly only in male ischemia compared to the sham group $(P<$ $0.05)$. DIZE in female rats caused no more significant reduction in body weight (BW) than the ischemia group. After ischemia total kidney weight in both female and male rats was decreased significantly $(P<0.05)$ but DIZE had no effect on total kidney weight (TKW). Ischemia and DIZE had no effect on gonad (testis or uterus) weight (Figures 4(a) and 4(b).

3.5. Effect of Renal I/R and DIZE Treatment on Oxidative Stress. Ischemia and reperfusion caused only significant increase in male serum MDA levels compared to the sham group and DIZE treatment depressed it when compared to the IR group $(19.27 \pm 2.6$ versus $9.15 \pm 2.01 \mu \mathrm{mol} / \mathrm{L}$ and $9.26 \pm 1.6$ versus $19.27 \pm 2.6 \mu \mathrm{mol} / \mathrm{L}, P<0.05$ ) (Figure 5(a)). Although administration of DIZE was decreased kidney MDA levels in male rats, but this difference was not statistically significant in compared to the ischemia group (Figures 5(a) and 5(b)).

3.6. Effect of Renal IR and DIZE Treatment on Kidney Histological Changes. The kidneys obtained from the I/R group (male and female rats) demonstrated obvious features of tubular damage compared to the sham group $(P<$ 0.05) (Figure 6). Preischemic treatment with DIZE reduced 

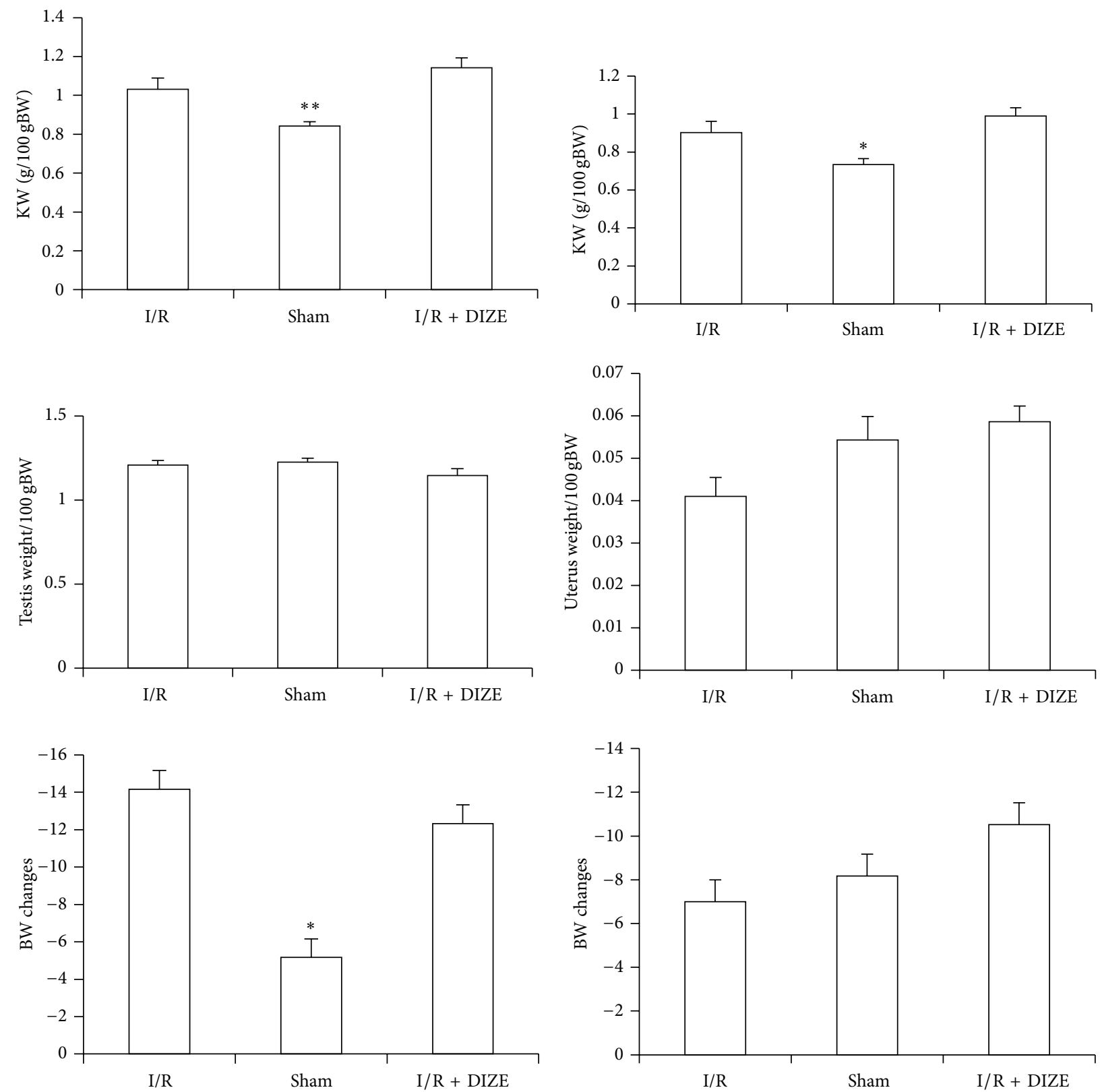

(a)

(b)

FIGURE 4: Total kidney weight (KW)/100 gr body weight, testis and uterus weight/100 gr body weight, and body weight changes in male (a) and female (b) I/R (45 min ischemia followed by 24 hours of reperfusion), sham operated, and diminazene ( $15 \mathrm{mg} / \mathrm{kg} / \mathrm{day}$ for 3 days) treated groups before ischemia (I/R + DIZE). ${ }^{*} P<0.05,{ }^{* *} P<0.01$ versus I/R group.

significantly the extent and severity of injury in male rats compared to the $\mathrm{I} / \mathrm{R}$ group $(P<0.05)$.

\section{Discussion}

The main objective of this research was to determine the effects of activation endogenous ACE2 using the DIZE in renal I/R injury. Several renoprotective anti-inflammatory effects of ACE2/Ang1-7/Mas receptor axis have been reported in kidney diseases suggesting that ACE2 may be playing role in kidney functions and renal hemodynamic regulation [18, 19]. ACE2 contributes to the balance of both RAS mediators, AngII and Ang1-7, because this enzyme can catabolize AngII to Ang1-7 which counteracts many pathophysiological effects of AngII [20]. Reduction of ACE2 expression or activity was observed in many acute kidney injures such as $I / R$ which support important role of ACE2 in renal I/R [21, 22]. Previous studies demonstrated the elevation of AngII and reduction of Ang1-7 levels in I/R injured animals [21, 23, 24]. Administration of recombinant human ACE2 has 

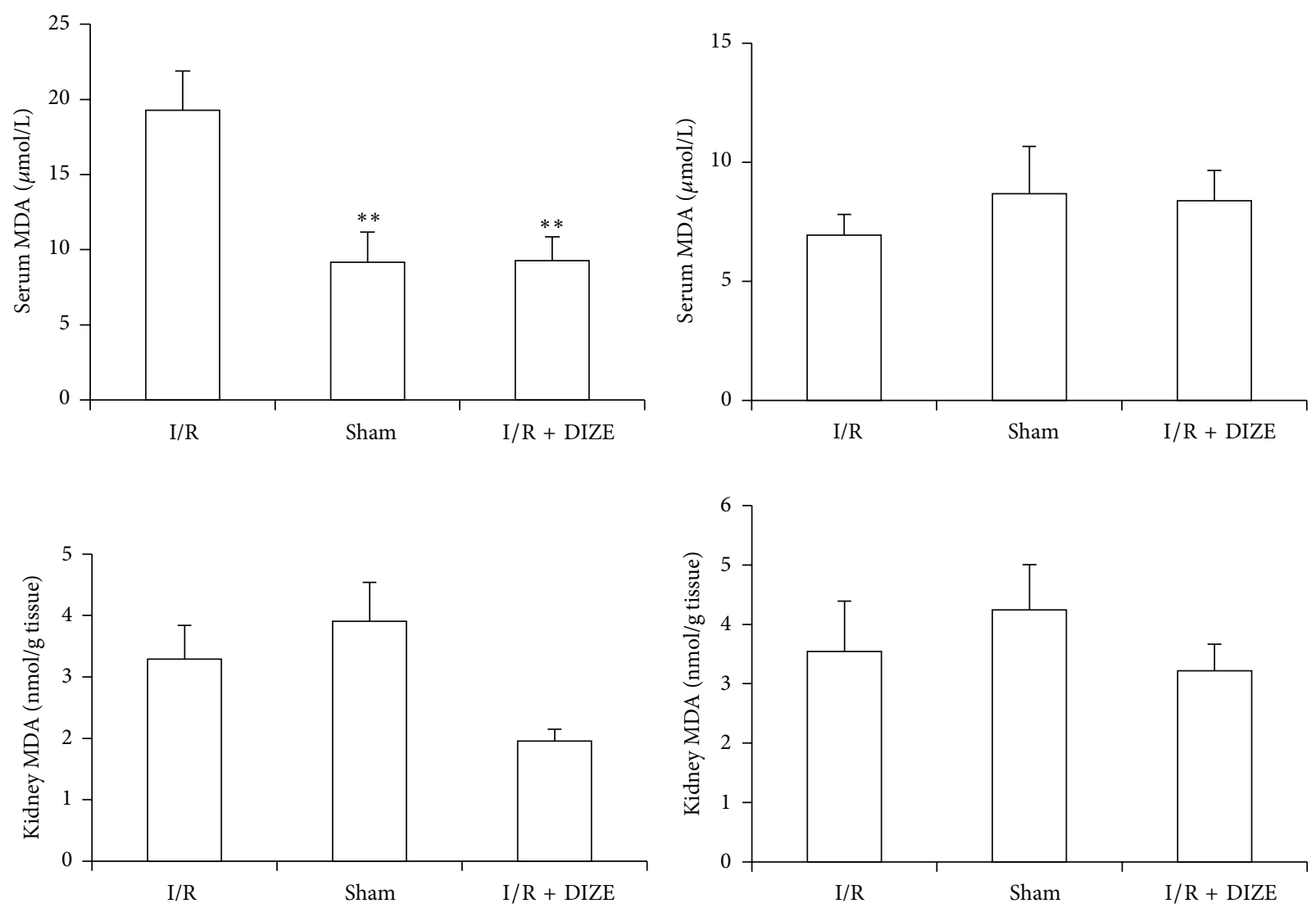

(a)

(b)

Figure 5: Changes in serum and kidney MDA levels in male (a) and female (b) I/R (45 min ischemia followed by 24 hours of reperfusion), sham operated, and diminazene ( $15 \mathrm{mg} / \mathrm{kg} /$ day for 3 days) treated groups before ischemia (I/R + DIZE). ${ }^{*} P<0.05,{ }^{* *} P<0.01$ versus I/R group.
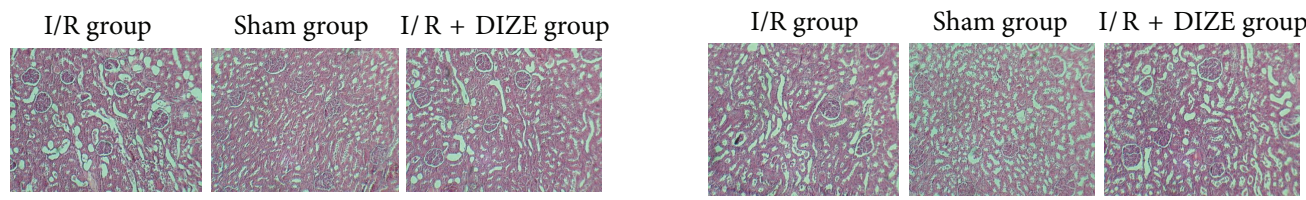

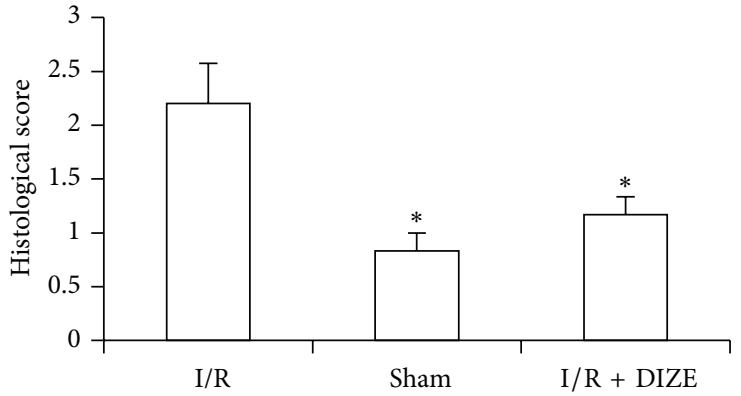

(a)

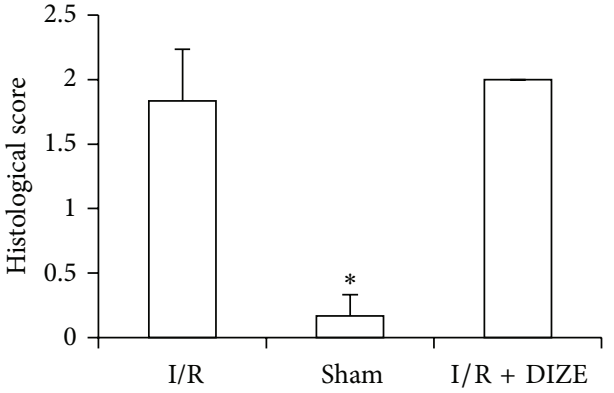

(b)

Figure 6: Histological evaluation of rat kidneys in male (a) and female (b) I/R (45 min ischemia followed by 24 hours of reperfusion), sham operated, and diminazene $\left(15 \mathrm{mg} / \mathrm{kg} /\right.$ day for 3 days) treated groups before ischemia (I/R + DIZE). ${ }^{*} P<0.05$ versus I/R group. 
been shown to mitigate injury in various disease models of elevated Ang II $[25,26]$. Qi et al. showed that DIZE treatment attenuated ischemia-induced cardiac pathophysiology [15]. These findings encourage us to investigate the effect of DIZE, a drug recently described as an activator of ACE2, with anti-inflammatory effects $[14,27]$ in renal $I / R$ injury. The elevation of serum urea and creatinine are the important early biomarkers in renal damages [28]. We demonstrated that DIZE was able to attenuate I/R-induced elevation of serum BUN and creatinine in male rats. The female rats displayed higher levels of creatinine compared to the $\mathrm{I} / \mathrm{R}$ group that indicated sex difference responses of DIZE. It is widely accepted that apoptosis is the major pathological change in renal I/R injury. In histological observations; the I/R group in both male and female rats demonstrated obvious features of acute tubular damage compared to the sham group that these histological alterations were significantly attenuated only in male treated rats with DIZE compared with the ischemia group. These difference responses may be because ovarian hormones can downregulate ACE2 mRNA expression in the kidney that augmented reduction of renal I/R-induced ACE2 expression [18, 21, 29] and led to lower renal ACE2 level in the female than male rats [5]. Consequently lower compensatory mechanisms attenuate the extent of damaging effects of AngII. In addition, studies showed that the serum and kidney ACE2 activity is sex dependent with higher activity in males compared to females [30, 31]. Previous studies showed that administration of the Ang1-7 agonist induced significant renoprotection in male mice, with diminished serum creatinine, decreased histological injury, and reduced renal and pulmonary leukocyte infiltration in renal ischemia/reperfusion [32].

Lipid peroxidation is an important pathway of reactive oxygen species inducing tissue injury after ischemic acute renal failure [33]. MDA is a stable and easily measurable marker of lipid peroxidation $[34,35]$. In this study the levels of kidney MDA were significantly increased in male I/R rats and DIZE treatment reversed the increase of MDA levels to a considerable extent near to sham group thereby confirming its antioxidant role in male I/R injury but not in female rats. Failure of other systems such as liver has shown followed by renal I/R [36]. Usually, the extent of hepatic damage is assessed by the increased level of cytoplasmic enzymes (ALT, AST, and ALP). In current study, increased serum hepatic enzymes levels after I/R were attenuated by DIZE treatment (significant decrease of ALT and ALP levels) in male rats, whereas there was the elevation of hepatic enzyme levels in $\mathrm{I} / \mathrm{R}$ female rats compared to sham group, but only AST showed significant difference and DIZE could not decrease these enzymes.

Nitrite represents a circulating and tissue storage form of nitric oxide (NO) liberated specifically during ischemia and is highly selective therapy agent with cytoprotection effects on tissue ischemia/reperfusion injuries [37-39]. Feng et al. have shown that ACE2 overexpression in brain increases NO synthesizes (both eNOS and nNOS) [40]. In addition of NO-mediated cytoprotection, nitrite may act via NOindependent pathways [41, 42]. Nitrite has optimal intrinsic biological activity at low $\mathrm{pH}$ or deoxyhemoglobin conditions such as those that occurred in ischemia [43]. It was reported that NOS activity and nitrite formation in isolated proximal tubule cells were enhanced by $15 \mathrm{~min}$ of hypoxia followed reoxygenation [44]. We demonstrated that DIZE treatment in female rats inhibited the increase of serum nitrite level after I/R but in male rats caused higher increase of kidney nitrite level after I/R. Therefore the difference in plasma and kidney nitrite levels after I/R may be another mechanism of contrasting response of DIZE treatment.

However, as mentioned based on many previous studies such as Fang et al. study [45], we assumed that the mechanism of diminazene action was the activation of ACE2 but Haber et al. showed that the beneficial action of diminazene on Ang IIinduced hypertension was ACE2 activity-independent [46]. Therefore, additional experiments will be required to better define the mechanism responsible for the protective effect of ACE2 in I/R.

\section{Conclusions}

Treatment with DIZE, an activator of ACE2, ameliorates male renal and liver functional impairment after renal I/R injury through enhancement nitrite levels and antioxidant activity but not in female rats, possibly due to gender differences in ACE2 activity and nitrite levels. Our results indicate that DIZE may be a novel therapeutic agent in male renal I/R injury.

\section{Conflict of Interests}

The authors declare that there is no conflict of interests regarding the publication of this paper.

\section{Acknowledgment}

This study was supported by Isfahan University of Medical Sciences.

\section{References}

[1] M. Agrawal and R. Swartz, "Acute renal failure," American Academy of Family Physicians, vol. 6, no. 7, pp. 2077-2088, 2000.

[2] G. M. Chertow, E. Burdick, M. Honour, J. V. Bonventre, and D. W. Bates, "Acute kidney injury, mortality, length of stay, and costs in hospitalized patients," Journal of the American Society of Nephrology, vol. 16, no. 11, pp. 3365-3370, 2005.

[3] M. Legrand, E. G. Mik, T. Johannes, D. Payen, and C. Ince, "Renal hypoxia and dysoxia after reperfusion of the ischemic kidney," Molecular Medicine, vol. 14, no. 7-8, pp. 502-516, 2008.

[4] R. Robert, D. A. Ghazali, F. Favreau, G. Mauco, T. Hauet, and J.-M. Goujon, "Gender difference and sex hormone production in rodent renal ischemia reperfusion injury and repair," Journal of Inflammation, vol. 8, article 14, 2011.

[5] K. D. Pendergrass, N. T. Pirro, B. M. Westwood, C. M. Ferrario, K. B. Brosnihan, and M. C. Chappell, "Sex differences in circulating and renal angiotensins of hypertensive mRen(2). Lewis but not normotensive Lewis rats," The American Journal of Physiology-Heart and Circulatory Physiology, vol. 295, no. 1, pp. H10-H20, 2008. 
[6] C. R. Cámara-Lemarroy, F. J. Guzmán-De La Garza, G. AlarcónGalván, P. Cordero-Pérez, and N. E. Fernndez-Garza, "Effect of sulfasalazine on renal ischemia/reperfusion injury in rats," Renal Failure, vol. 31, no. 9, pp. 822-828, 2009.

[7] M. S. Paller, J. R. Hoidal, and T. F. Ferris, "Oxygen free radicals in ischemic acute renal failure in the rat," The Journal of Clinical Investigation, vol. 74, no. 4, pp. 1156-1164, 1984.

[8] M. A. Daemen, C. van’t Veer, G. Denecker et al., "Inhibition of apoptosis induced by ischemia-reperfusion prevents inflammation," The Journal of Clinical Investigation, vol. 104, no. 5, pp. 541$549,1999$.

[9] J. Kontogiannis and K. D. Burns, "Role of AT1 angiotensin II receptors in renal ischemic injury," American Journal of Physiology: Renal Physiology, vol. 274, no. 1, pp. F79-F90, 1998.

[10] C. M. Ferrario and J. Varagic, "The ANG-(1-7)/ACE2/mas axis in the regulation of nephron function," American Journal of Physiology: Renal Physiology, vol. 298, no. 6, pp. F1297-F1305, 2010.

[11] M. I. Phillips and S. Kagiyama, "Angiotensin II as a proinflammatory mediator," Current Opinion in Investigational Drugs, vol. 3, no. 4, pp. 569-577, 2002.

[12] C. Lavoz, R. Rodrigues-Diez, A. Benito-Martin et al., "Angiotensin II contributes to renal fibrosis independently of notch pathway activation," PLoS ONE, vol. 7, no. 7, Article ID e40490, 2012.

[13] X.-H. Yang, Y.-H. Wang, J.-J. Wang et al., "Role of angiotensinconverting enzyme (ACE and ACE2) imbalance on tourniquetinduced remote kidney injury in a mouse hindlimb ischemiareperfusion model," Peptides, vol. 36, no. 1, pp. 60-70, 2012.

[14] S. Kuriakose and J. E. Uzonna, "Diminazene aceturate (Berenil), a new use for an old compound?" International Immunopharmacology, vol. 21, no. 2, pp. 342-345, 2014.

[15] Y. Qi, J. Zhang, C. T. Cole-Jeffrey et al., "Diminazene aceturate enhances angiotensin-converting enzyme 2 activity and attenuates ischemia-induced cardiac pathophysiology," Hypertension, vol. 62, no. 4, pp. 746-752, 2013.

[16] M. M. Yeboah, X. Xue, B. Duan et al., "Cholinergic agonists attenuate renal ischemia-reperfusion injury in rats," Kidney International, vol. 74, no. 1, pp. 62-69, 2008.

[17] P. Jablonski, B. O. Howden, D. A. Rae, C. S. Birrell, V. C. Marshall, and J. Tange, "An experimental model for assessment of renal recovery from warm ischemia," Transplantation, vol. 35, no. 3, pp. 198-204, 1983.

[18] S. V. B. Pinheiro and A. C. Simões E Silva, "Angiotensin converting enzyme 2, angiotensin-(1-7), and receptor mas axis in the kidney," International Journal of Hypertension, vol. 2012, Article ID 414128, 8 pages, 2012.

[19] J. Zhang, N. A. Noble, W. A. Border, and Y. Huang, "Infusion of angiotensin-(1-7) reduces glomerulosclerosis through counteracting angiotensin II in experimental glomerulonephritis," American Journal of Physiology: Renal Physiology, vol. 298, no. 3, pp. F579-F588, 2010.

[20] R. A. S. Santos, A. J. Ferreira, and A. C. S. E Silva, "Recent advances in the angiotensin-converting enzyme 2angiotensin(1-7)-Mas axis," Experimental Physiology, vol. 93, no. 5, pp. 519-527, 2008.

[21] K. D. Da Silveira, K. S. P. Bosco, L. R. L. Diniz et al., "ACE2angiotensin-(1-7)-mas axis in renal ischaemia/reperfusion injury in rats," Clinical Science, vol. 119, no. 9, pp. 385-394, 2010.

[22] E. Velskoska, R. G. Dean, L. Burchill, V. Levidiotis, and L. M. Burrell, "Reduction in renal ACE2 expression in subtotal nephrectomy in rats is ameliorated with ACE inhibition," Clinical Science, vol. 118, no. 4, pp. 269-279, 2010.

[23] S. Efrati, S. Berman, R. A. Hamad et al., "Effect of captopril treatment on recuperation from ischemia/reperfusion-induced acute renal injury," Nephrology Dialysis Transplantation, vol. 27, no. 1, pp. 136-145, 2012.

[24] Z. Wang, Y. Liu, Y. Han et al., "Protective effects of aliskiren on ischemia-reperfusion-induced renal injury in rats," European Journal of Pharmacology, vol. 718, no. 1-3, pp. 160-166, 2013.

[25] D. Batlle, J. Wysocki, M. J. Soler, and K. Ranganath, "Angiotensin-converting enzyme 2: enhancing the degradation of angiotensin II as a potential therapy for diabetic nephropathy," Kidney International, vol. 81, no. 6, pp. 520-528, 2012.

[26] G. J. Rey-Parra, A. Vadivel, L. Coltan et al., "Angiotensin converting enzyme 2 abrogates bleomycin-induced lung injury," Journal of Molecular Medicine, vol. 90, no. 6, pp. 637-647, 2012.

[27] L. V. Kulemina and D. A. Ostrov, "Prediction of off-target effects on angiotensin-converting enzyme 2," Journal of Biomolecular Screening, vol. 16, no. 8, pp. 878-885, 2011.

[28] R. W. Schrier, W. Wang, B. Poole, and A. Mitra, "Acute renal failure: definitions, diagnosis, pathogenesis, and therapy," Journal of Clinical Investigation, vol. 114, no. 1, pp. 5-14, 2004.

[29] K. B. Brosnihan, J. B. Hodgin, O. Smithies, N. Maeda, and P. Gallagher, "Tissue-specific regulation of ACE/ACE2 and AT1/AT2 receptor gene expression by oestrogen in apolipoprotein E/oestrogen receptor- $\alpha$ knock-out mice," Experimental Physiology, vol. 93, no. 5, pp. 658-664, 2008.

[30] J. Liu, H. Ji, W. Zheng et al., "Sex differences in renal angiotensin converting enzyme 2 (ACE2) activity are $17 \beta$-oestradioldependent and sex chromosome-independent," Biology of Sex Differences, vol. 1, no. 1, article 6, 2010.

[31] A. Soro-Paavonen, D. Gordin, C. Forsblom et al., "Circulating ACE2 activity is increased in patients with type 1 diabetes and vascular complications," Journal of Hypertension, vol. 30, no. 2, pp. 375-383, 2012.

[32] L. C. Barroso, K. D. Silveira, C. X. Lima et al., "Renoprotective effects of AVE0991, a nonpeptide Mas receptor agonist, in experimental acute renal injury," International Journal of Hypertension, vol. 2012, Article ID 808726, 8 pages, 2012.

[33] D. Grekas, C. Dioudis, G. Papageorgiou et al., "Lipid peroxidation after acute renal ischemia and reperfusion in rats: the effect of trimetazidine," Renal Failure, vol. 18, no. 4, pp. 545-552, 1996.

[34] S. Gaweł, M. Wardas, E. Niedworok, and P. Wardas, "Malondialdehyde (MDA) as a lipid peroxidation marker," Wiadomosci Lekarskie, vol. 57, no. 9-10, pp. 453-455, 2004.

[35] P. Seth, R. Kumari, S. Madhavan et al., "Prevention of renal ischemia-reperfusion-induced injury in rats by picroliv," Biochemical Pharmacology, vol. 59, no. 10, pp. 1315-1322, 2000.

[36] H. T. Hassoun, D. N. Grigoryev, M. L. Lie et al., "Ischemic acute kidney injury induces a distant organ functional and genomic response distinguishable from bilateral nephrectomy," American Journal of Physiology-Renal Physiology, vol. 293, no. 1, pp. F30-F40, 2007.

[37] M. R. Duranski, J. J. M. Greer, A. Dejam et al., "Cytoprotective effects of nitrite during in vivo ischemia-reperfusion of the heart and liver," The Journal of Clinical Investigation, vol. 115, no. 5, pp. 1232-1240, 2005.

[38] K.-H. Jung, K. Chu, S.-Y. Ko et al., "Early intravenous infusion of sodium nitrite protects brain against in vivo ischemiareperfusion injury," Stroke, vol. 37, no. 11, pp. 2744-2750, 2006. 
[39] P. Tripatara, N. S. A. Patel, A. Webb et al., "Nitrite-derived nitric oxide protects the rat kidney against ischemia/reperfusion injury in vivo: role for xanthine oxidoreductase," Journal of the American Society of Nephrology, vol. 18, no. 2, pp. 570-580, 2007.

[40] Y. Feng, H. Xia, Y. Cai et al., "Brain-selective overexpression of human angiotensin-converting enzyme type 2 attenuates neurogenic hypertension," Circulation Research, vol. 106, no. 2, pp. 373-382, 2010.

[41] N. S. Bryan, B. O. Fernandez, S. M. Bauer et al., "Nitrite is a signaling molecule and regulator of gene expression in mammalian tissues," Nature Chemical Biology, vol. 1, no. 5, pp. 290-297, 2005.

[42] M. T. Gladwin, "Nitrite as an intrinsic signaling molecule," Nature Chemical Biology, vol. 1, no. 5, pp. 245-246, 2005.

[43] J. W. Calvert and D. J. Lefer, "Myocardial protection by nitrite," Cardiovascular Research, vol. 83, no. 2, pp. 195-203, 2009.

[44] L. Yu, P. E. Gengaro, M. Niederberger, T. J. Burke, and R. W. Schrier, "Nitric oxide: a mediator in rat tubular hypoxia/reoxygenation injury," Proceedings of the National Academy of Sciences of the United States of America, vol. 91, no. 5, pp. 1691-1695, 1994.

[45] F. Fang, G. C. Liu, X. Zhou et al., "Loss of ACE2 exacerbates murine renal ischemia-reperfusion injury," PLoS ONE, vol. 8, no. 8, Article ID e71433, 2013.

[46] P. K. Haber, M. Ye, J. Wysocki, C. Maier, S. K. Haque, and D. Batlle, "Angiotensin-converting enzyme 2-independent action of presumed angiotensin-converting enzyme 2 activators: studies in vivo, ex vivo, and in vitro," Hypertension, vol. 63, no. 4, pp. 774-782, 2014. 


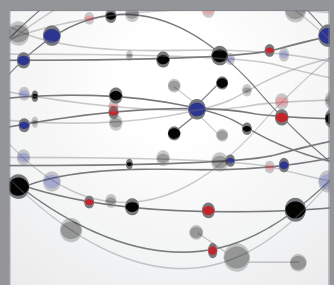

The Scientific World Journal
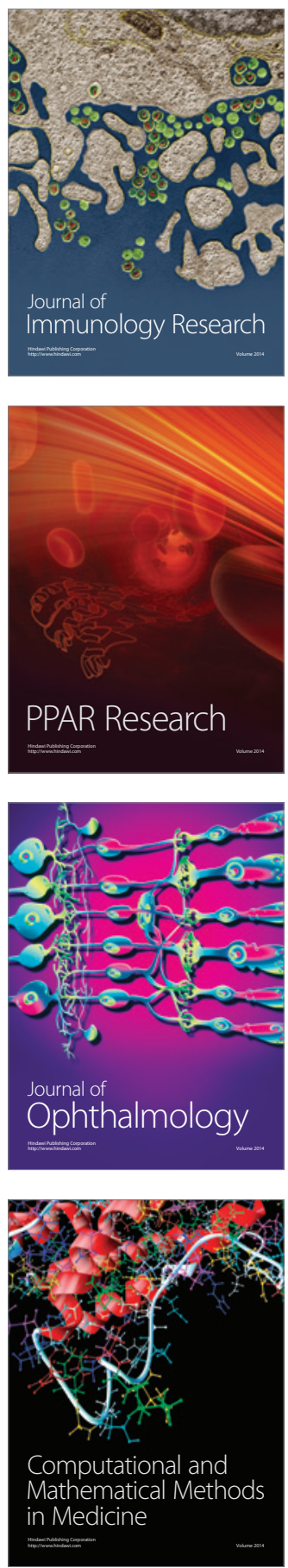

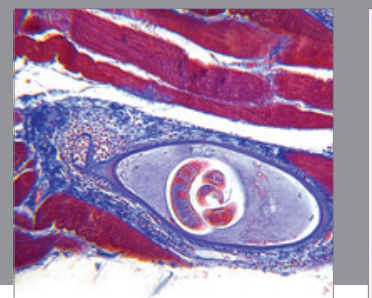

Gastroenterology

Research and Practice
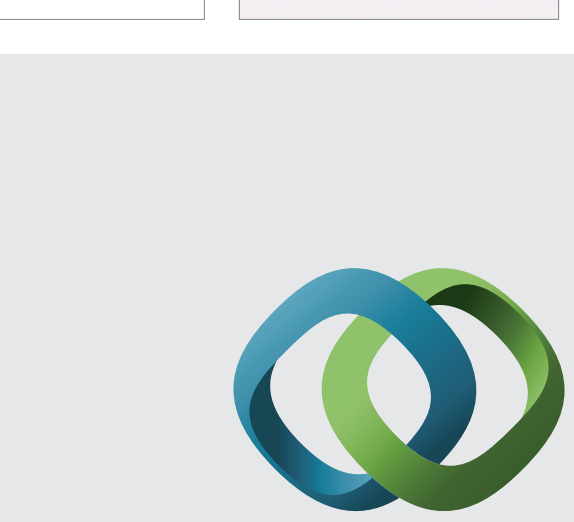

\section{Hindawi}

Submit your manuscripts at

http://www.hindawi.com
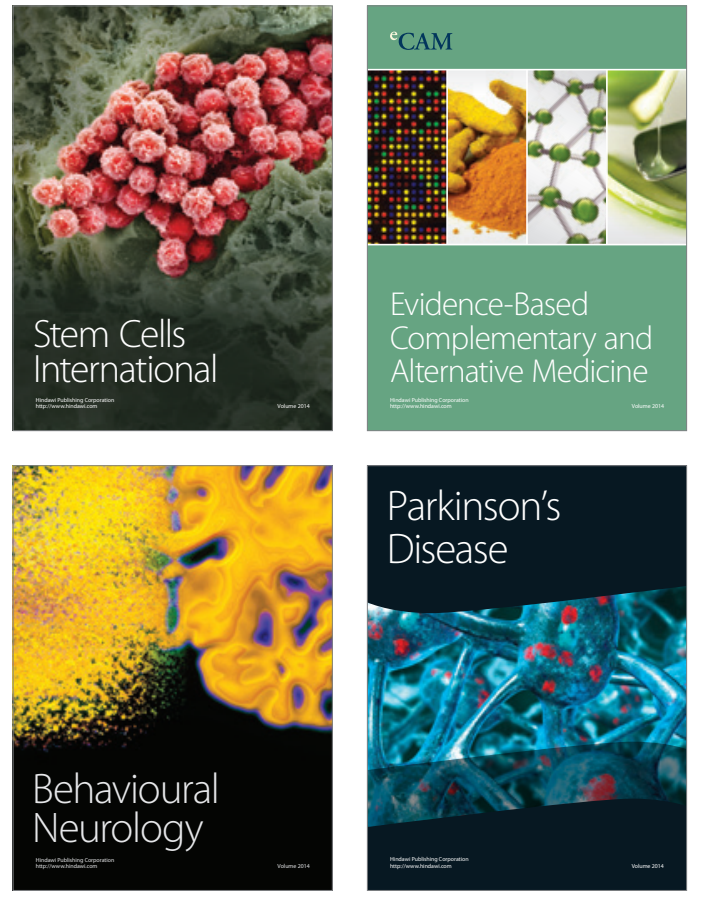
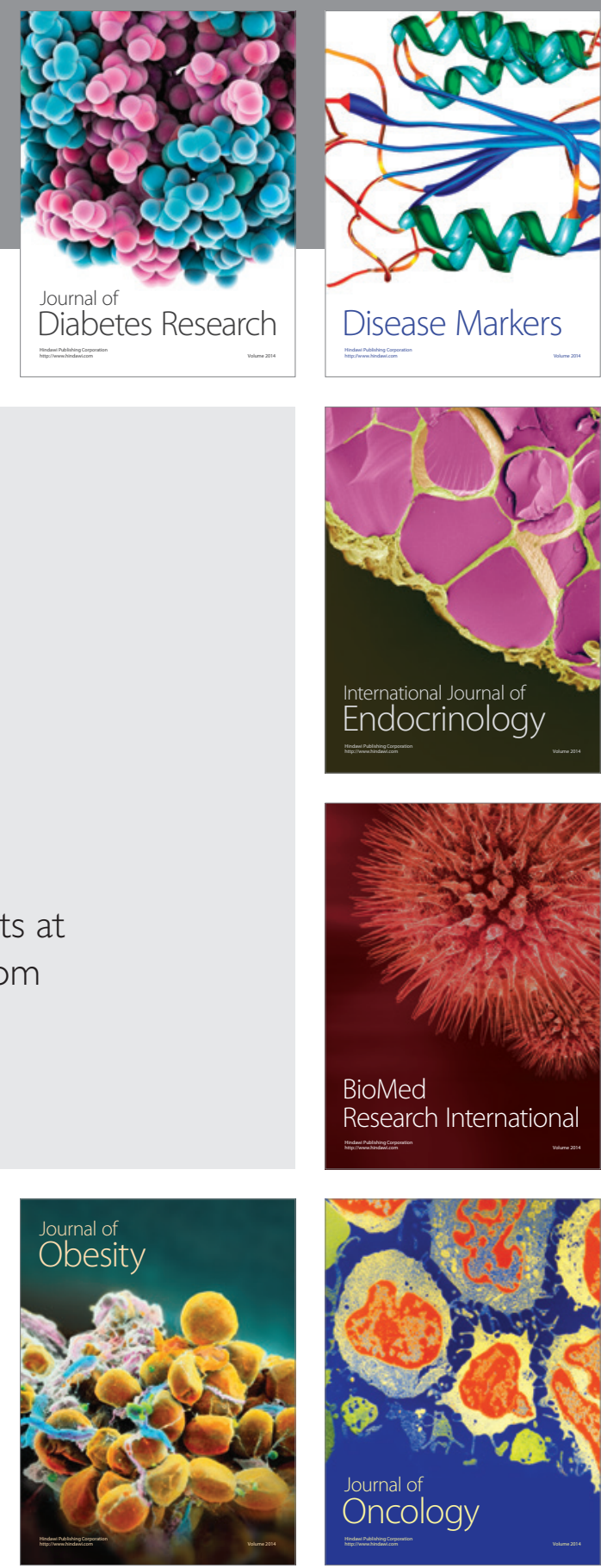

Disease Markers
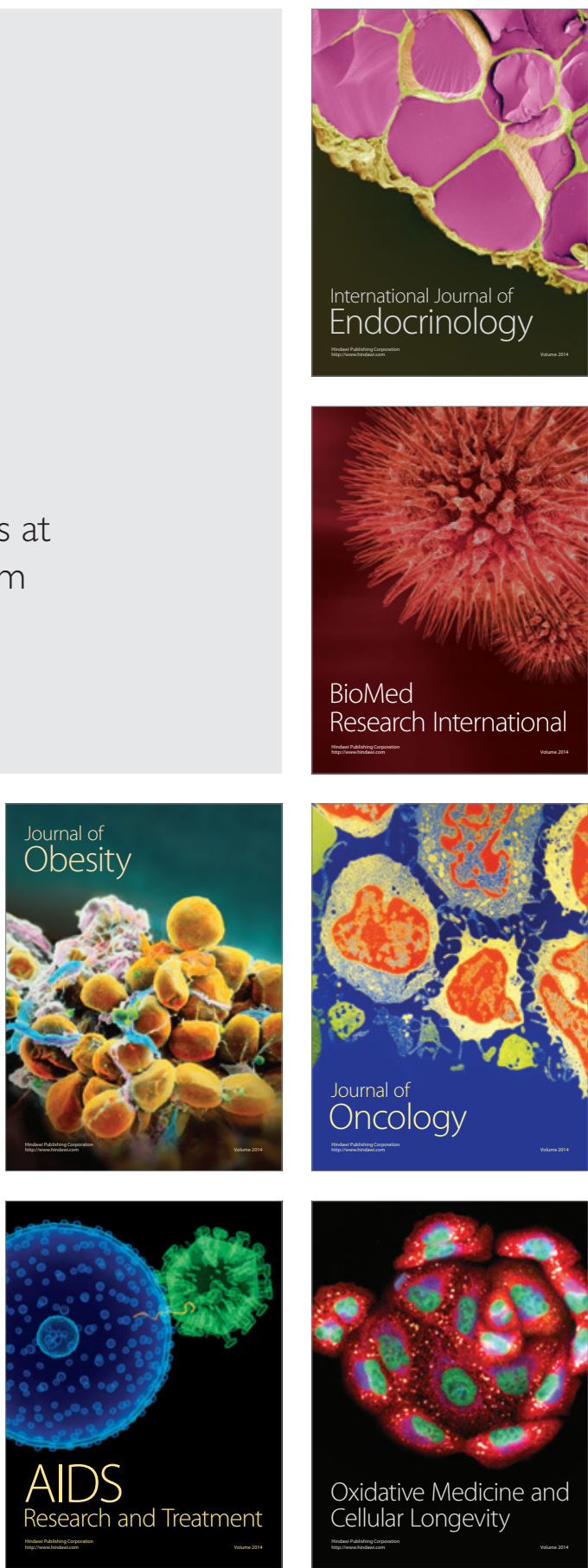